\title{
ESTATUTO DO PERTENCIMENTO BRASILEIRO: IDENTIFICANDO MENTALIDADES E REPRESENTAÇÕES EM PRÁTICAS CONTEMPORÂNEAS
}

\author{
Ana Clara Correa Henning* \\ Mônica Anselmi Duarte da Silva** \\ Thais Luzia Colaço***
}

SUMÁRIO: Introdução; 2 Olbar Proprietário: Influências Iluministas e Modernas em Terras Brasileiras; 3 Interpretando Constitucionalmente o Estatuto do Pertencimento: Função Social da Propriedade; 4 Do Conceito Unitário de Propriedade à Pluralidade de Pertencimentos; 5 Pertencimento Jurídico: Práticas Locais e Reconbecimento Legal; 6 Considerações Finais; Referências.

RESUMO: Propõe-se, aqui, que a maneira pela qual conhecemos determinado sistema jurídico, e o direito privado que lhe é próprio, constitui-se em mentalidades e representações oriundas de um substrato cultural que é, ao mesmo tempo, resultado de um certo pensamento e instrumentos de produção desse mesmo pensamento. Nessa esteira, a concepção moderna do direito de propriedade está historicamente condicionada a um determinado paradigma, advindo do embate entre a dogmática cristã e a racionalidade de pensamento, especialmente construído entre os séculos XVI eXIX. Durante esse período, presencia-se uma profunda mudança epistemológica na maneira de se construir ciência e de se visualizar o papel do regramento jurídico no Ocidente. Hoje, compreende-se necessário repensar o formalismo daí resultante, a fim de enriquecer a compreensão do direito com o reconhecimento de inúmeras variáveis socioantropológicas. No que concerne ao tema deste artigo, mapear representações ou mentalidades do estatuto do pertencimento brasileiro torna-se um dos diversos exemplos de uma nova percepção do sistema jurídico.

PALAVRAS-CHAVE: Estatuto Jurídico do Pertencimento no Brasil; Mentalidades; Representações; Variáveis Socioantropológicas.

\footnotetext{
Doutoranda em Direito pela Universidade Federal de Santa Catarina (UFSC); Bolsista CAPES; E-mail: anaclaracorreahenning@gmail.com

** Docente de Graduação em Direito e de Pós-Graduação em Direito Civil e Processo Civil da Faculdade Anhanguera de Pelotas; Advogada.

**** Docente do Programa de Pós-Graduação em Direito Stricto Sensu da Universidade Federal de Santa Catarina (UFSC); Doutora em Direito pela Universidade Federal de Santa Catarina (UFSC) e Pós-Doutora em Direito (Universidad de Sevilla)
} 


\title{
BRAZILIAN STATUTE OF BELONGING: IDENTIFICATION OF MENTALITIES AND REPRESENTATIONS IN CONTEMPORARY PRACTICE
}

\begin{abstract}
The manner we acknowledge a determined juridical system and its rights is formed by mentalities and representations derived from a cultural substrate which, in its turn, is the result of a certain type of thought and production tools of the former. The modern concept of the right of property is historically conditioned to a certain paradigm caused by the conflict between Christian doctrine and rationality, constructed between the $16^{\text {th }}$ and $19^{\text {th }}$ centuries. A deep epistemological change occurred during this period in the construction of science and the materialization of juridical rules in the Western world. The ensued formalism should be re-thought to enrich the understanding of Law with the acknowledgement of innumerable social and anthropological variables. Mapping the representations or mentalities of the Brazilian statute of belonging is one of the many examples within a new perception of the juridical system.
\end{abstract}

KEY WORDS: Mentalities; Representations; Social and Anthropological Variables; Juridical Statute of Belonging in Brazil.

\section{ESTATUTO DE PERTENENCIA BRASILEÑA: IDENTIFICANDO MENTALIDADES Y REPRESENTACIONES EN PRÁCTICAS CONTEMPORÁNEAS}

RESUMEN: Se propone, aquí, que la forma cómo conocemos determinado sistema jurídico y su derecho privado, se constituye en mentalidades y representaciones oriundas de un substrato cultural que es, al mismo tiempo, resultado de determinado pensamiento y de los instrumentos de producción de este mismo pensamiento. En este proceso, la concepción moderna del derecho de propiedad está históricamente condicionada a un determinado paradigma, procedente del embate entre la dogmática cristiana y la racionalidad del pensamiento, especialmente construido entre los siglos XVI y XIX. Durante ese período, se presencia un profundo cambio epistemológico en la forma como se construye ciencia y se visualiza el papel reglamentar jurídico del Occidente. Actualmente, se comprende que es necesario repensar el formalismo resultante de ese proceso para enriquecer la comprensión del derecho como el reconocimiento de innúmeras variables socio-antropológicas. En lo que se refiere al tema de este artículo, mapear las representaciones o mentalidades del estatuto de pertenencia brasileña se vuelve uno de los diversos ejemplos de una nueva percepción del sistema jurídico.

PALABRAS-CLAVE: Mentalidades; Representaciones; Variables Socio-antropológicas; Estatuto Jurídico de Pertenencia en Brasil. 


\section{INTRODUÇÃO}

O estatuto do pertencimento é foco de intensos debates sociais nas mais diversas áreas do conhecimento. Sua dimensão interdisciplinar reflete-se nos inúmeros artigos científicos de fundo antropológico e sociológico publicados antes e após a Constituição Federal de 1988, tendo por base a necessidade de conexão entre o direito e o mundo dos fatos.

Ao sistema jurídico, tal dimensão torna-se um desafio, por relevantes motivos. A estrutura jurídica moderna, herdeira da mentalidade e das representações iluministas dos oitocentos, possui uma vertente privatista fortemente enraizada, que dá primazia a institutos como a propriedade privada. Essa forma de construir o direito dificulta a abertura a outros saberes (considerados meramente não jurídicos) e obstaculiza a permeabilidade dos valores constitucionais na elaboração e interpretação das normas de direito civil.

Reconhecem-se, entretanto, formas de pertencimento exercidas contemporaneamente em diversas partes do território nacional que contrariam tal lógica, partindo de pressupostos tais como a solidariedade e a utilização coletiva da terra. Sua análise não poderá, portanto, resumir-se à técnica do direito, devendo contemplar, igualmente, variáveis socioantropológicas.

É sob esta perspectiva que se desenvolve o presente texto, o qual está fundamentado em uma revisão teórica interdisciplinar. Inicialmente, são referidas as bases iluministas do direito moderno de propriedade e a centralidade social do proprietário. Em seguida, é ressaltada a necessidade de uma virada hermenêutica na compreensão do direito civilista, iluminado, agora, pelas regras constitucionais, do que decorre a importância central da função social da propriedade. São discutidos, igualmente, os conceitos unitário e pluralista de propriedade para, ao final, serem indicadas algumas formas de pertencimento efetivadas no território brasileiro, com características locais e diferenciadas da metanarrativa do direito de propriedade moderno.

\section{OLHAR PROPRIETÁRIO: INFLUÊNCIAS ILUMINISTAS E MODERNAS EM TERRAS BRASILEIRAS}

A visão de mundo do ser humano se faz sentir não só na sua fala ou escrita, como também nas suas ações e estratégias escolhidas para a construção 
desse universo, segundo seus interesses e representações ${ }^{1}$. As percepções dos atores sociais, especialmente a partir do contexto histórico-social da classe a que pertencem, são elementos fundamentais para a compreensão de suas manifestações e comportamentos em relação aos discursos próximos ou contrapostos.

Nessa esteira de pensamento, é relevante o conceito de mentalidade, proposto por Paolo Grossi. Conforme as palavras do autor, um "complexo de valores circulantes em uma área espacial e temporal capaz, pela sua vitalidade, de superar a diáspora dos fatos e episódios espalhados e de constituir o tecido conectivo escondido e constante daquela área, e deve, portanto ser colhido como realidade unitiva"2. A mentalidade de certas classes, assim, concretamente constrói e desconstrói mundos, estabelece regramentos sociais, edifica sistemas jurídicos.

Observe-se o Medievo, por exemplo: deve-se reconhecer a grande estatura que a Igreja Católica detinha, acarretando, dentre outras consequências, o poder clerical, a imposição dogmática e o argumento de autoridade. O direito canônico era soberano em diversos litígios, estendendo-se do direito privado aos processos inquisitoriais efetivados contra os hereges. Além disso, dentro dos mosteiros havia uma intensa atividade cultural e intelectual. ${ }^{3}$

Por outro lado, no que tange ao direito de propriedade, ainda que existentes diversos territórios sob domínio da Igreja Cristã, coexistiam inúmeras formas de pertencimento, onde múltiplos sujeitos detinham poderes diferenciados sobre a mesma coisa, muitas vezes baseados em regras consuetudinárias, em um "brotar desordenado e vivo de situações rústicas”‘ . Não havia um Estado unificador, mas diversos feudos, mais (ou menos) autônomos frente ao poder real e ao religioso.

Foi apenas entre os séculos XVI e XVII que alguns cientistas naturais romperam com dogmas religiosos, desvendando os mistérios que regiam a natureza e elaboraram fundamentos racionais para eventos explicados através da fé. Simplificação e quantificação tornaram-se palavras de ordem. As ferramentas das ciências exatas serviram bem a tal empreendimento:

\footnotetext{
1 A categoria "representação", conceito sociológico de Pierre Bourdieu aqui utilizado para compreender a visão de mundo e o discurso do sujeito proprietário, tem dupla face, a mental e a objetal. A primeira liga-se aos "atos de percepção e de apreciação, de conhecimento e reconhecimento, em que os atores investem seus interesses e pressupostos" e a segunda às coisas simbólicas e aos atos, enquanto "estratégias interessadas de manipulação simbólicas tendentes a determinar a representação (mental) que os outros podem construir a respeito tanto dessas propriedades como de seus portadores". BOURDIEU, Pierre. A economia das trocas linguísticas: o que falar quer dizer. São Paulo: EDUSP, 1996, p. 107-108.

2 GROSSI, Paolo. História da Propriedade e Outros Ensaios. Rio de Janeiro: Renovar, 2006, p. 30.

3 DAVID, René. Os Grandes Sistemas do Direito Contemporâneo. Tradução de Hermínio A. Carvalho. $3^{a}$ ed. São Paulo: Martins Fontes, 1996.

4 GROSSI, Paolo. História da Propriedade e Outros Ensaios. Rio de Janeiro: Renovar, 2006, p. 14.
} 
As ideias que presidem à observação e à experimentação são as ideias claras e simples a partir das quais se pode ascender a um conhecimento mais profundo e rigoroso da natureza. Essas ideias são as ideias matemáticas. [...] Em primeiro lugar, conbecer significa quantificar. O rigor científico afere-se pelo rigor das medições. As qualidades intrínsecas do objeto são, por assim dizer, desqualificadas e em seu lugar passam a imperar as quantidades que eventualmente se podem traduzir. O que não é quantificável é cientificamente irrelevante. Em segundo lugar, o método científico assenta na redução da complexidade. O mundo é complicado e a mente humana não o pode compreender completamente. Conhecer significa dividir e classificar para depois poder determinar relações sistemáticas entre o que se separou (Grifo nosso) ${ }^{5}$.

A classe que ascendeu ao lugar da construção do conhecimento constituiuse de homens livres, imbuídos da missão de desbravar as leis do Universo e apropriarse da natureza e de todos os bens que a eles devem servir. Através disso, adquiriram a condição legitimadora de reproduzir seu ideário e representações no espaço público do debate das ideias racionais, tidas como únicas verdades aceitáveis ${ }^{6}$.

Compreende-se, assim, que o pensamento iluminista, nascido no berço da burguesia, fundou o conhecimento científico-jurídico moderno, cujos alicerces legitimadores estão calcados no raciocínio lógico e autônomo, apartados das antigas fontes divinas e transcendentes, delineando o perfil privatista e patrimonialista do direito ${ }^{7}$. Ele categorizou conhecimentos, negando status científico a saberes que não fossem produzidos por suas regras metodológicas, impondo valores europeus a outros povos. Seus reflexos no direito ainda persistem visíveis nas mais diversas interpretações de institutos jurídicos contemporâneos ${ }^{8}$.

Tal modelo forjou a configuração atual do direito de propriedade. Após a complexidade do sistema proprietário medieval, a reestruturação do instituto realizada pelo direito moderno pretendeu imprimir-lhe a maior simplificação possível $^{9}$, em um esforço próprio da mentalidade moderna. Aos perfis da propriedade medieval sucedeu uma configuração menos complexa, simplificando o direito e

\footnotetext{
5 SANTOS, Boaventura de Sousa. A Crítica da razão indolente: contra o desperdício da experiência. Para um Novo Senso Comum: a ciência, o direito e a política na transição paradigmática. 3. ed. São Paulo: Cortez, 2001, p. 63.

6 KANT, Immanuel. Resposta à pergunta: que é esclarecimento? Disponível em: <www.ufsm.br/gpforma/2senafe/PDF/b47.pdf > . Acesso em: 03 jan. 2015 (sem indicação do tradutor).

7 HESPANHA, António Manuel. Cultura jurídica europeia: síntese de um milénio. 3. ed. Mem Martins: Europa -América, 2003.

8 COLAÇO, Thais Luzia; DAMÁZIO, Eloise da Silveira Petter. Novas perspectivas para a antropologia jurídica na América Latina: o direito e o pensamento decolonial. Florianópolis: Fundação Boiteux, 2012.

9 GROSSI, Paolo. História da propriedade e outros ensaios. Rio de Janeiro: Renovar, 2006.
} 
estabelecendo-lhe uma racionalidade essencialmente econômica. A coisa deveria pertencer a apenas uma pessoa ${ }^{10}$, ao ponto de o Código Napoleônico não regular o condomínio (referindo-se apenas à indivisão pós-mortem) por receio de possibilitar a emergência de uma propriedade coletiva ${ }^{11}$.

Para o liberalismo clássico, a igualdade formal presumia que todos poderiam deter sua titularidade e utilizá-la da forma como melhor aprouvessem, desde que fossem respeitadas as normatizações vigentes. Havia, portanto, certos limites ao seu uso, ainda que a Declaração de Direitos do Homem e do Cidadão (1789), categorizando-a como direito natural, considerasse a propriedade "inviolável e sagrada"12.

Esse conhecimento científico-jurídico construído na modernidade, europeu por excelência, foi a fonte do direito brasileiro, inobstante as diferenças culturais e sociológicas. No Código Civil brasileiro de 1916, a inspiração francesa pode ser identificada no art. 524: "a lei assegura ao proprietário o direito de usar, gozar e dispor de seus bens, e de reavê-los do poder de quem quer que, injustamente, os possua" 13 - jus utendi, jus fruendi $\mathrm{e}$ jus abutendi. Tal escolha não se deu por acaso: a classe proprietária sempre exerceu sua influência nos textos jurídicos.

A origem do direito de propriedade no Brasil, especialmente sobre a terra, vem da apropriação por concessão e "apoderamento", cuja legalização posterior o Estado se encarregou de fornecer. Esse direito de propriedade, amplo e irrestrito, foi legitimado formalmente e passou a valer como verdade indiscutível e absoluta. $\mathrm{O}$ proprietário, sujeito da classe oriunda dos colonizadores que aqui se estabeleceram, edificou suas mentalidades e representações através dessa prática apropriacionista, que culminou por se estabelecer legalmente, garantida pelo marco jurídico europeu aqui vigente. Com isso, passou a reforçar esse conceito sobre todas as coisas que dele se tornem pertenças, bem como opor esse direito erga omnes, ou seja, contra todos e contra tudo, conforme o artigo civilista transcrito acima.

Sob tal paradigma, a propriedade e a posse da terra passaram a valer como um elemento de identificação, de distinção e de poder; seu exercício foi legitimado

\footnotetext{
${ }_{10}$ RODOTÁ, Stefano. El Terrible Derecho: estúdios sobre la propriedad privada. Tradução de Díez-Picazo. Madrid: Civitas, 1986.

11 ADROGUÉ, Manuel I. El Derecho de Propriedad em la Actualidad: introduccion a sus nuevas expressiones. Buenos Aires: Abeledo-Perrot, 1991.

${ }^{12}$ GILISSEN, John. Introdução Histórica ao Direito. Tradução de António Manuel Hespanha e L. M. Macaísta Malheiros. 4. ed. Lisboa: Fundação Calouste Gulbenkian, 2003, p. 635.

13 BEVILAQUA, Clóvis. Código Civil dos Estados Unidos do Brasil Comentado por Clóvis Bevilaqua. Edição Histórica. Rio de Janeiro: Rio, 1979.
} 
contra o não proprietário ou não possuidor e contra o próprio Estado legitimador, constituindo um espaço institucional e social de lutas simbólicas, bem como um elemento do capital social, material e imaterial desse ator ${ }^{14}$. O caráter privado da propriedade, sua amplitude e intensidade de exercício, enquanto direito, tornou-se gradualmente uma característica indissociável, interiorizada e exteriorizada pelos sujeitos e absorvido como valor e verdade indubitável do grupo social para e pelo o qual o direito foi construído.

Assim, a mentalidade dos indivíduos se constrói a partir de sua posição na sociedade, e da sua inclusão no rol dos sujeitos de direitos. A representação do direito de propriedade liga-se, então, à posição social do sujeito proprietário, ou seja, a partir de sua condição institucional, social e econômica dentro da sociedade. Esse sistema de representações duradouras, e ao mesmo tempo substituíveis, conjugando as experiências passadas com as necessidades reais do presente, servindo como uma matriz permanente de percepções e ações práticas, Bourdieu chama de habitus. Ele é um "sistema simbólico que é organizado segundo a lógica da diferença, do desvio diferencial" ${ }^{15}$, servindo como instrumento de reforço desse direito de propriedade, traduzido na compreensão e na adoção de práticas destinadas a reiterar as diferenças a ele atribuídas.

Depreende-se daí que direito e sujeito modernos construíram o ideário de uma propriedade absoluta, restrita e oficialmente conceituada e definida pela lei. Colonizado pelo Iluminismo e pelas ciências jurídicas europeias, o sistema jurídico brasileiro absorveu o conceito de propriedade e entregou esse direito, exclusivamente, à classe proprietária brasileira, primeiramente representada pelo proprietário rural, deixando de fora todo aquele sujeito não pertencente a essa classe social.

O pertencimento das coisas, dos bens da vida, foi imposto por códigos direcionados a uma persona ideal, definido por um conhecimento alienígena que desconheceu a realidade local, resultando na abstração do substrato social. Resultado disso é a negação de polissemias e de imprevisibilidades. A noção eminentemente privada do instituto da propriedade foi construída sob este pressuposto, imprimindo sua conceituação, os poderes do proprietário e os princípios de direitos das coisas aos quais se submete. Esse distanciamento leva à pretensão de neutralidade, à negação da complexidade, à miséria do direito:

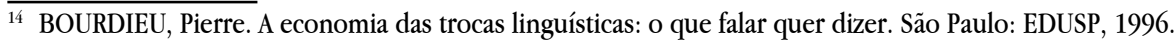

15 BOURDIEU, Pierre. A economia das trocas linguísticas: o que falar quer dizer. São Paulo: EDUSP, 1996, p. 160. 
A metódica constitucional debate-se ainda com aquilo que já se chamou epigonismo positivista. Por mais que se faça fé numa metodologia pós-positivista que vá para além dos textos, os operadores jurídicos mostram-se relapsos em ultrapassar os postulados positivistas: (1) as soluções dos casos encontram-se nos textos das normas; (2) a interpretação/aplicação de normas é a aplicação da regra geral e condicional precisa e suficientemente definida nos 'códigos'. Quem assim proceder não sabe nada de direito constitucional (grifos no original) ${ }^{16}$.

Ainterpretação do direito é, nas palavras de Canotilho (2003), muito maior do que a mera aplicação do texto legal previsto nos códigos. Estes, preponderantemente, comportam um conhecimento que pressupõe a homogeneidade e a ausência de descontinuidades e rupturas. Tais entendimentos não se adequaram a uma hermenêutica que se proponha condizente com a multiplicidade de relações sociais que produzem o mundo atual.

\section{INTERPRETANDO CONSTITUCIONALMENTE O ESTATUTO DO PERTENCI- MENTO: FUNÇÃO SOCIAL DA PROPRIEDADE}

A percepção e aplicação das normas constitucionais é, contemporaneamente, perpassada por uma virada hermenêutica, o que se torna especialmente difícil tendo em vista o histórico de colonização que formou a sociedade brasileira. Como visto, o direito europeu configurava-se como centro da representação, projetando-se e conformando outros sistemas, dentro de cada nação europeia e, mesmo, fora desse continente, em grande parte devido às inúmeras colônias além-mar. Daí os estudos hoje desenvolvidos a respeito do pós-colonialismo. A esse respeito, Norbert Rouland afirma:

[...] o direito é deste mundo. Mas os homens de 1789 o creem no mundo inteiro. A Declaração dos Direitos do Homem é universalista. Laico, idêntico para todos porque fundamentado na Natureza e na Razão universal, o direito que ela inspira tem vocação para exportação. Primeiro na Europa, graças às conquistas napoleônicas; mais tarde muito mais longe, pela colonização (ainda hoje, legislações inteiras de estados da África negra são calcadas no Código Civil, e para dizer a verdade pouco aplicadas) ${ }^{17}$.

\footnotetext{
${ }^{16}$ CANOTILHO, José Joaquim Gomes. Direito Constitucional e Teoria da Constituição. 7. ed. Coimbra: Almedina, 2003, p. 119.

17 ROULAND, Norbert. Nos Confins do Direito. Tradução de Maria Ermantina de Almeida Prado Galvão. 2. ed. São Paulo: Martins Fontes, 2008, p. 64.
} 
Nessa constatação reside, por exemplo, a importância da reflexão sobre princípios constitucionais, como o da função social da propriedade, além da concretização de práticas distributivas de justiça. Não é de se admirar que grande parte da população brasileira não se submeta (nem mesmo conheça) a regramentos jurídico-civilistas, já que estes possuem pouca aplicação aos não proprietários. "A massa da população excluída dos supostos benefícios da população civil tende a desenvolver um ordenamento próprio para reger seus (pequenos) interesses, desprezados pela legislação oficial" ${ }^{18}$.

É necessário, assim, não somente ressaltar a constituição iluminista da propriedade privada, mas identificar e analisar as situações nas quais uma nova maneira de configuração de pertencimento se manifesta no direito brasileiro. A referência pioneira a uma função a ser submetida à propriedade vem de León Duguit (1912), o qual defendia que esta existe para suprir uma necessidade econômica; modificada a necessidade, modifica-se a propriedade. Daí que, em sua época, o autor constatava que de uma dimensão estritamente individual, a propriedade se convertia em funcionalização social ${ }^{19}$.

Prevista inicialmente na Constituição do México $(1917)^{20}$ e da Alemanha $(1919)^{21}$, essa funcionalização foi albergada na Constituição brasileira de 1934. Seguiram-se às Constituições de 1937, 1946, 1967, a Emenda Constitucional n ${ }^{0} 01$ de 1969 e a atual Constituição de 1988. Dentre as legislações infraconstitucionais,

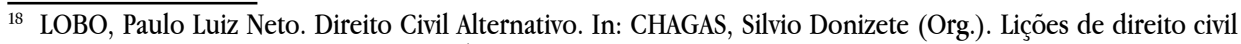
alternativo. São Paulo: Acadêmica, 1994, p. 15.

19 DUGUIT, León. Las Transformaciones Generales del Derecho Privado desde el Código de Napoleón. 2. ed. Tradução de Carlos Pousada. Madrid: Francisco Beltran Libreria, 1912.

${ }^{20}$ Constituição Mexicana de 1917, art. 27: "A propriedade das terras e águas compreendidas dentro dos limites do território nacional, corresponde originariamente a Nação, a qual teve e tem o direito de transmitir o domínio delas aos particulares, constituindo a propriedade privada. As expropriações só poderão ocorrer devido a utilidade pública e mediante indenização. A Nação terá em todo tempo o direito de impor a propriedade privada as modalidades que dite o interesse público, assim como de regular, em benefício social, o aproveitamento dos elementos naturais suscetíveis de apropriação, com objetivo de fazer uma distribuição equitativa da riqueza pública, cuidar de sua conservação, alcançar o desenvolvimento equilibrado do país e o melhoramento das condições de vida da população rural e urbana". No original: "La propiedad de las tierras y aguas comprendidas dentro de los límites del território nacional, corresponde originariamente a la Nación, la cual ha tenido y tiene el derecho de transmitir el dominio de ellas a los particulares, constituyendo la propiedad privada. Las expropiaciones sólo podrán hacerse por causa de utilidad pública y mediante indemnización. La nación tendrá en todo tiempo el derecho de imponer a la propiedad privada las modalidades que dicte el interés público, así como el de regular, en beneficio social, el aprovechamiento de los elementos naturales susceptibles de apropiación, con objeto de hacer una distribución equitativa de la riqueza pública, cuidar de su conservación, lograr el desarrollo equilibrado del país y el mejoramiento de las condiciones de vida de la población rural y urbana". MÉXICO. Constituição Mexicana de 1917. Disponível em: http://www.diputados. gob.mx/LeyesBiblio/pdf/1.pdf. Acesso em: 23 nov. 2014. Tradução livre das autoras.

${ }^{21}$ Constituição de Weimar, art. 153: "A Constituição garante a propriedade. O seu conteúdo e os seus limites resultam de lei. [...] A propriedade obriga e seu uso e exercício devem, ao mesmo tempo, representar uma função no interesse social". Referido por PAULSEN, Leandro. A Normatividade Jurídico-Positiva da Função Social da Propriedade. Revista da AJUFERGS, Porto Alegre, n. 02, p. 61-106, 2006. p. 68. 
encontra-se no Estatuto da Terra (Lei $\mathrm{n}^{0} 4.504 / 1964$ ), que exigiu a produtividade da propriedade rural e no Código Civil de 2002, além do citado art. 1.228, o art. 2.035, parágrafo único ${ }^{22}$. Em meio a diversas disposições legais, na sua aplicação leva-se em conta uma interpretação sistemática do instituto da propriedade:

Todos estes valores que atingem as gerações atuais e futuras devem, necessariamente, compor o exercício do direito de propriedade, inclusive valores históricos e artísticos. A função social da propriedade se preenche de ações desenvolvidas com base nestes valores sociais $^{23}$.

A contemporânea sede constitucional do direito de propriedade e de sua funcionalização encontra-se no art. $5^{\circ}$, XXII (garantia da propriedade privada) e XXIII (função social da propriedade), no art. 170, II e III (princípios da ordem econômica), nos art. 184 e 186 (função social da propriedade rural). Apesar disso, surpreendentemente ou não, no que tange à propriedade, o Código Civil de 2002 pouco inovou. A força da mentalidade e das representações proprietárias transparece na doutrina quando entende que a Parte Especial do Livro III do CC/2002 (Direito das Coisas) é a parte mais conservadora da codificação, em comparação com os demais livros e também com sistemas jurídicos estrangeiros ${ }^{24}$.

O Código dispôs sobre a propriedade no caput do art. 1.228, com grande correspondência ao texto do art. 524, acima transcrito. O parágrafo primeiro impõe a sua funcionalização, prevendo a preservação, dentre outros valores, do patrimônio histórico e artístico. Nos parágrafos $2^{\circ}$ a $5^{\circ}$ indica suas limitações: 0 parágrafo segundo impede a utilização que atente contra direito de outrem ou que não traga ao seu titular qualquer comodidade ou utilidade. Os parágrafos seguintes, terceiro, quarto e quinto, discriminam a possibilidade de desapropriação, com justa indenização ao proprietário.

A modificação na letra da legislação proprietária brasileira, percebe-se, não se deu de maneira ampla (nota-se, inclusive, pela semelhança entre os art. 524 e 1.228, respectivamente do Código anterior e do atual), sendo a percepção iluminista de propriedade pouco modificada. E, no entanto, a repersonalização do direito civil

${ }^{22}$ ORLEANS, Helen Cristina Leite de Lima. Não Basta ser Proprietário, Tem que Participar: algumas notas sobre a função social da propriedade imobiliária no Direito brasileiro. Revista de Direito Privado, São Paulo, ano 12, v. 46, p. 99-147, abr./jun. 2011.

${ }^{23}$ ALVIM, Arruda. Livro Introdutório ao Direito das Coisas e o Direito Civil. Vol. XI, Tomo I. In: ALVIM, Arruda; ALVIM, Thereza; CLÁPIS, Alexandre Laizo (Coord.). Comentários ao Código Civil Brasileiro. Rio de Janeiro: Forense, 2009, p. 116-117.

${ }^{24}$ ALVIM, Arruda. Livro Introdutório ao Direito das Coisas e o Direito Civil. Vol. XI, Tomo I. In: ALVIM, Arruda; ALVIM, Thereza; CLÁPIS, Alexandre Laizo (Coord.). Comentários ao Código Civil Brasileiro. Rio de Janeiro: Forense, 2009. 
alcança igualmente seus regramentos. A necessidade de interpretar esse direito a partir dos valores constitucionais e situações fáticas suscita inúmeras discussões na literatura especializada.

Em primeiro lugar, faz-se menção ao debate sobre existência de limites à propriedade tradicionalmente concebida. Autores entendem que os diversos valores constitucionais, especialmente a função social da propriedade (art. $5^{\circ}$, XXIII e 170, III), impõem limitações das mais variadas formas aos poderes, agora faculdades, do proprietário $^{25}$. Os exemplos do direito de vizinhança e da preservação do patrimônio histórico são seguidamente mencionados. Por outro lado, há quem perceba esse direito qualitativamente transformado, tendo os valores constitucionais migrados para o interior do seu conceito, de maneira que:

Fica evidenciado que a função social não se resume à regra programática, como se possa pensar, mas integra a essência do instituto, assentada na concretude da situação proprietária, levadas em conta o papel desempenhado pelo sujeito proprietário, seja nas suas relações com os demais sujeitos sociais, seja em relação ao bem apropriado (grifo nosso) ${ }^{26}$.

Pietro Perlingieri afirma que essa funcionalização não se traduz em intervenção contrária à propriedade, mas na razão de sua existência. O proprietário somente possui a titularidade porque o Estado assim o quis ${ }^{27}$. Ela não é imanente ao homem, mas estatalmente concedida para o seu benefício e de toda a sociedade, pela Constituição Federal ${ }^{28}$. Ou seja: a terra tem de ser utilizada, tendo por base valores constitucionais, construindo-se um conceito dinâmico dessa funcionalização, abarcando diversas obrigações do proprietário. Tendo em vista esse dever imposto pela Carta Magna - agora, parte do próprio conceito de propriedade - a questão da sua função social deve ser analisada conjuntamente com a função social da posse.

Compreende-se que, ao se referir a essa temática, a funcionalização da propriedade comporta sua utilização, remetendo à maneira como as faculdades do proprietário serão exercidas ${ }^{29}$. A função social da posse, diferentemente

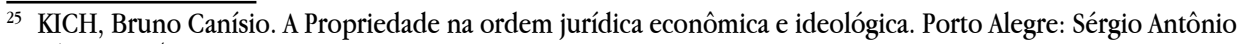
Fabris, 2004.

${ }^{26}$ LIMA, Getúlio Targino. Propriedade: crise e reconstrução de um perfil conceitual. São Paulo: SRS, 2009, p. 71-72.

27 PERLINGIERI, Pietro. O Direito Civil na Legalidade Constitucional. Tradução de Maria Cristina de Cicco. Rio de Janeiro: Renovar, 2008.

${ }^{28}$ MENDES, Gilmar Ferreira; COELHO, Inocêncio Mártires; BRANCO, Paulo Gustavo Gonet. Curso de direito constitucional. 5. ed. São Paulo: Saraiva, 2010.

${ }^{29}$ FACHIN, Luiz Edson. A função social da posse e da propriedade contemporânea: uma perspectiva da usucapião imobiliária rural. Porto Alegre: Sérgio Antônio Fabris, 1988.
} 
da propriedade, não está explicitamente prevista na Carta Constitucional. Sua apreensão ocorre "através da interpretação do direito e do poder criador que deve ser reconhecido a toda a interpretação judicial, que pautará sua conclusão fora dos métodos tradicionais da hermenêutica" ${ }^{\text {"30 }}$. Ingo Wolfgang Sarlet refere a denominação "direitos decorrentes do regime e dos princípios constitucionais"31 (nos termos do $\S$ $2^{\circ}$, art. $5^{\circ}, \mathrm{CF} / 88$ ). A função social da posse, assim, está protegida no sistema jurídico brasileiro a partir de uma compreensão sistemática dos art. $1^{\circ}$, III; $5^{\circ}$, XXIII e 170 da $\mathrm{CF} / 88$, segundo seu objetivo de promoção da cidadania e dignidade.

Mas a doutrina vai além, indagando sobre o conteúdo dessa função.

Elencada como direito fundamental (art. $5^{\circ}, \mathrm{XXIII}, \mathrm{CF} / 88$ ), como princípio da ordem econômica (170, III, CF/88) e nos arts. 182 (Política Urbana), 184 e 186 (Política Agrícola e Fundiária) da Carta, a função social da propriedade vem sendo interpretada pelo viés econômico. Ou seja, a propriedade deve proporcionar benefícios materialmente auferidos, tal como a destinação econômica da terra, avaliada por sua produtividade. Mas, da mesma forma, ela deve ser útil ao contexto da sociedade em seu entorno. Há, assim, a necessidade de "estabelecer os critérios para identificar o que pode obedecer à lógica do mercado e o que, ao contrário, não pode ser reduzido a uma mercadoria" ${ }^{2}$. Para Rodotá, isto se aplica à composição entre direitos proprietários e não proprietários, alcançando, inclusive, gerações futuras.

$\mathrm{Na}$ dimensão que lhe reconhecemos, a função social da propriedade ultrapassa tal encaixe e abrange, igualmente, um espaço cultural, com significado diferente daquele de exploração econômica. Note-se que "o poder de usar um bem não é unívoco, já que o uso e o gozo dependerão do papel desempenhado pelo proprietário e da espécie de bem apropriada"33. As formas de uso, portanto, são flexibilizadas, sob conformação dos valores constitucionais, inclusive o da função social de que aqui se fala.

A propriedade também possui representação, de vieses históricos, de

$\overline{30}$ TORRES, Marcos Alcino de Azevedo. A Propriedade e a Posse: um confronto em torno da função social. 2. ed. Rio de Janeiro: Lumen Juris, 2010, p. 387.

31 SARLET, Ingo Wolfgang. A Eficácia dos direitos fundamentais: uma teoria geral dos direitos fundamentais na perspectiva constitucional. 10. ed. Porto Alegre: Livraria do Advogado, 2010, p. 89.

32 RODOTÁ, Stefano. El Terrible Derecho: estúdios sobre la propriedad privada. Tradução de Díez-Picazo. Madrid: Civitas, 1986, p. 07.

${ }^{33}$ CORTIANO JÚNIOR, Eroulhts. O discurso jurídico da propriedade e suas rupturas: uma análise do ensino do Direito de Propriedade. Rio de Janeiro: Renovar, 2001, p. 159. 
ressignificação da memória e de ancestralidade ${ }^{34}$. É o que ocorre com a propriedade rural quilombola, por exemplo. Em seu substrato encontram-se inúmeros valores constitucionais, como o da dignidade humana e da igualdade, fundamentando uma dimensão coletiva, de convivência e luta comuns ${ }^{35}$, absolutamente diversas do proprietário tradicional e individualista. Cabe razão a Perlingieri quando afirma:

A tentativa de reduzir o significado da função social da propriedade a um critério de sadia gestão econômica é prejudicada também pela lógica utilitarista e produtivista [...]. Considerada a centralidade, no sistema constitucional, do valor da pessoa e a consequente funcionalização das situações patrimoniais - propriedade e empresa - às situações existenciais, também a disciplina da pertinência (appartenenza) e da utilização dos "bens econômicos" dos particulares deve ser funcional ao escopo, sem se limitar a realizar maior produtividade e/ou relações sociais mais justas ${ }^{36}$.

A impossibilidade da redução da função social da propriedade ao único prisma da exploração econômica fica bem exemplificada em acórdão referido por Tepedino e Schreiber: apesar de ser a área produtiva, seu proprietário possuía débitos fiscais federais, entendendo-se que esse descumprimento da funcionalização possibilitava a manutenção do assentamento de seiscentas famílias carentes naquele terreno ${ }^{37}$.

\section{DO CONCEITO UNITÁRIO DE PROPRIEDADE À PLURALIDADE DE PERTEN- CIMENTOS}

Uma segunda discussão na doutrina contemporânea problematiza se é possível identificar um conceito unitário (tradicional) de propriedade ou se, ao contrário, deve-se contemporaneamente falar em propriedades, acentuando-se aqui o plural. As duas principais correntes doutrinárias serão aqui apresentadas.

\footnotetext{
34 CIRNE, Mariana Barbosa. A (Pré) compreensão de uma propriedade que trabalha contra sua função social. In: CONGRESSO NACIONAL DE PESQUISA E PÓS-GRADUAÇÃO EM DIREITO, 19., 2010, Fortaleza. Anais.... Florianópolis, Fundação Boiteux, 2010. Disponível em: < http://www.conpedi.org.br/manaus/arquivos/anais/ fortaleza/Integra.pdf > . Acesso em: 02 jan. 2015.

35 PILATI, José Isaac. Propriedade e função social na pós-modernidade. 2. ed. Rio de Janeiro: Lumen Juris, 2012.

${ }^{36}$ PERLINGIERI, Pietro. O Direito Civil na Legalidade Constitucional. Tradução de Maria Cristina de Cicco. Rio de Janeiro: Renovar, 2008, p. 939.

37 TEPEDINO, Gustavo; SCHREIBER, Anderson. A Garantia da Propriedade no Direito Brasileiro. Revista da Faculdade de Direito de Campos, ano VI, n. 06, p. 101-119, jun., 2005.
} 
Paolo Grossi entende pela pluralidade proprietária: a propriedade individual seria apenas uma das múltiplas formas encontradas nos mais variados sistemas jurídicos. Apenas a consideramos, segundo ele, a única porque é a que está em nosso horizonte etnocêntrico, lá situada, especialmente, via Code francês de 1804. Tendo por precursor Salvatore Pugliatti, cuja obra possui um subtítulo denominado "A propriedade e as propriedades" 38 , Grossi desenvolve sua teoria:

Olhemos por um momento em contra-luz nosso título. "A" propriedade e "as" propriedades: um singular e um plural, estranhamente associados, pelo menos na linguagem habitual da ciência jurídica italiana; se não em oposição, ao menos em função abertamente dialética. Um singular humilhado e depauperado por aquele plural, mas que não desaparece nele; um plural que adquire seu significado mais pleno somente se confrontado com e referindo-se àquele singular. Um instituto, em suma, do qual se deve sublinhar a relatividade, mas que é sempre uma relatividade incompleta, porque aquele plural é sempre obrigado a ajustar as contas com aquele singular, sempre sobre aquelas propriedades grava a sombra ameaçadora $\mathrm{d} a$ propriedade $^{39}$.

Essa visão pluralista da propriedade entende que os estatutos proprietários variam de acordo com o objeto e o sujeito da relação jurídica. O primeiro, abarcando uma infinidade de bens materiais e imateriais, passando por imóveis e títulos de crédito, por exemplo; o útlimo, constituindo-se em entes públicos e privados, sociedades empresariais, pessoas físicas, comunidades.

Stefano Rodotá é ainda mais enfático ao defender a pluralidade proprietária: "Não é possível limitar-se a 'rasgar o véu' da propriedade única: subsiste sempre a necessidade de explicar como pode-se acreditar durante decênios na tese da unidade de conceito de propriedade não obstante a existência de disciplinas setoriais diferenciadas" ${ }^{\prime 4}$.

Tal compreensão é compartilhada por José Isaac Pilati. Partindo do pressuposto que a estrutura atual do direito proprietário no Brasil é dicotômica, dividindo a categoria de bens em públicos e privados (art. 92 do CC/2002), o autor afirma o surgimento de uma nova categoria, a das propriedades especiais:

\footnotetext{
38 PUGLIATTI, Salvatore. La Proprietà nel Nuovo Diritto. Milano: Dott. A. Giuffrè, 1964.

39 GROSSI, Paolo. História da propriedade e outros ensaios. Rio de Janeiro: Renovar, 2006, p. 11.

${ }^{40}$ No original: "No es posible limitarse a 'rasgar el velo' de la propiedad única: subsiste simpre la necesidad de explicar cómo ha podido acreditarse durante decenios la tesis de la unidad de concepto de propriedad no obstante la existencia de disciplinas sectoriales diferenciadas". RODOTÁ, Stefano. El Terrible Derecho: estúdios sobre la propriedad privada. Tradução de Díez-Picazo. Madrid: Civitas, 1986, p. 51. Tradução livre das autoras.
} 
bens que possuem um estatuto híbrido, com fundamento constitucional próprio, sem regramentos conectados diretamente aos preceitos civilistas ou de cunho administrativo. As propriedades especiais possuem uma gestão coletiva e sua forma de apropriação faz com que seja revisitada a noção preponderantemente econômica da função social da propriedade, especialmente, segundo Pilati, quando se observa a propriedade quilombola e indígena ${ }^{41}$.

De outra forma, Marcos Alcino de Azevedo Torres (2010) defende um conceito unitário, no sentido que o núcleo da propriedade é um só, devendo cada caso ser enquadrado a partir das delimitações legais ${ }^{42}$. No mesmo sentido, Arruda Alvim afirma que "o que se quer dizer é que a noção unitária diz com a essência e com elementos definitórios nucleares, ao passo que, a segunda, diz com o perfil concreto e diferenciado que diversas situações de direito de propriedade assumem”“33.

Tupinambá Nascimento (2003), por sua vez, observa que o CC/2002 descreve as faculdades do proprietário, mas não conceitua propriedade. Tais faculdades (uso, fruição, disposição) podem, inclusive, nem ser exercidas, persistindo o direito. Daí conceituá-la de maneira unitária, da seguinte forma: "consiste na titularidade, ou senhorio jurídico, da substância da coisa". Por substância entende-se a "identidade física do bem, sua configuração físico-estética” ${ }^{\prime 4}$.

Pode-se, a partir daqui, tecer algumas considerações. A propriedade é dinâmica, traduzindo-se em uma relação jurídica complexa, não mais se resumindo a um direito subjetivo ilimitado. Depende do substrato material e cultural em que está inserida e dos deveres do proprietário frente ao ente estatal, aos não proprietários e demais proprietários.

Essa nova mentalidade, esse novo "complexo de valores circulantes em uma área espacial e temporal" ${ }^{45}$, permite representações que conectam práticas sociais, alteridades e traduz-se, também, em modificações legislativas, textos doutrinários e decisões judiciais. Assim, a constitucionalização do direito privado pode ser observada tanto na elaboração de leis e na sua interpretação sob as lentes constitucionais, quanto na presença na Constituição de institutos tradicionalmente de direito privado.

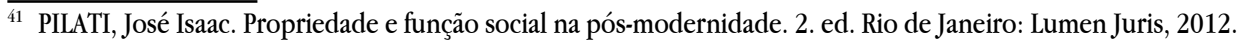

${ }^{42}$ TORRES, Marcos Alcino de Azevedo. A Propriedade e a posse: um confronto em torno da função social. 2. ed. Rio de Janeiro: Lumen Juris, 2010.

${ }^{43}$ ALVIM, Arruda. Livro Introdutório ao Direito das Coisas e o Direito Civil. Vol. XI, Tomo I. In: ALVIM, Arruda; ALVIM, Thereza; CLÁPIS, Alexandre Laizo (Coord.). Comentários ao Código Civil Brasileiro. Rio de Janeiro: Forense, 2009, p. 43.

${ }^{44}$ NASCIMENTO, Tupinambá Miguel Castro do. Posse e propriedade. 3. ed. Porto Alegre: Livraria do Advogado, 2003, p. 112.

${ }^{45}$ GROSSI, Paolo. História da propriedade e outros ensaios. Rio de Janeiro: Renovar, 2006.
} 
Compreende-se, sob esta perspectiva, a CF/88 como norma superior do ordenamento, permeada de valores, cuja eficácia deve ser garantida pelos poderes estatais e, mesmo, por particulares e por coletividades ou grupos de pessoas ${ }^{46}$. Assim, "o objetivo da Constituição deixa de ser, única e exclusivamente, o de estabelecer o Estado de Direito e limitar o poder político e passa a ser o de estabelecer a moldura da atividade dos indivíduos" ${ }^{\prime 7}$.

Ainda que o direito das coisas, especialmente no que diz respeito à propriedade, pouco tenha sofrido modificações em seu texto, a força da Constituição se faz sentir na elaboração e interpretação do Código Civil de 2002. Princípios (agora, civilistas) como o da sociabilidade, eticidade e operabilidade tornam-se básicos para a correta estruturação do direito privado brasileiro ${ }^{48}$ : este será aplicado na concretude social, entre pessoas reais, não abstratas, que devem se pautar, em suas relações jurídicas, de maneira ética e solidária. A redação do Código procura torná-lo de mais fácil operabilidade, suprimindo, muitas vezes, dúvidas oriundas da codificação anterior e facilitando sua interpretação ${ }^{49}$.

Metanarrativas não explicam o complexo traçado de que os direitos reais são compostos. Grupos se fazem ouvir, reivindicando formas próprias de cidadania, elaborando práticas e teorias ao invés de adotar aquelas que lhes foram impostas ${ }^{50}$. Tal entendimento direciona a visão do jurista, considerando não mais o direito como coerente, exato, completo. Sua interpretação - sua consolidação - ocorre através da participação do hermeneuta, ao reconhecer a realidade cultural dos destinatários das normatizações. Nisso, ele se assemelha com o investigador, partindo do pressuposto que:

[...] um paradigma dá performance ao olhar do(a) pesquisador(a) e influencia seu modo de ver a realidade e até mesmo sua capacidade de interrogá-la. Colocando-se dentro de um paradigma positivista ou fenomenológico, as perguntas de pesquisa que o(a) pesquisador(a) considerará possível formular serão radicalmente diferentes, pois a concepção de realidade é diferente, assim, como divergem as ideias

46 BARATA, Pedro Paulo Barradas. A Constituição e o Código Civil: reflexões sobre a eficácia dos direitos fundamentais. Revista de Direito Privado, São Paulo, ano 10, n. 37, p. 185-207, jan./mar. 2009.

47 ANDRADE, Fabio Siebeneichler de. Considerações sobre a Tutela dos Direitos da Personalidade no Código Civil de 2002. In: SARLET, Ingo Wolfgang (Org.). O Novo Código Civil e a Constituição. 2. ed. Porto Alegre: Livraria do Advogado, 2006, p. 103.

${ }^{48}$ CORTIANO JÚNIOR, Eroulhts. O Discurso jurídico da propriedade e suas rupturas: uma análise do ensino do Direito de Propriedade. Rio de Janeiro: Renovar, 2001.

${ }^{49}$ LISBOA, Roberto Senise. Dignidade e Solidariedade Civil-Constitucional. Revista de Direito Privado, São Paulo, ano 11, v. 42, p. 30-70, abr./jun., 2010.

${ }^{50}$ COLAÇO, Thais Luzia; DAMÁZIO, Eloise da Silveira Petter. Novas perspectivas para a antropologia jurídica na América Latina: o direito e o pensamento decolonial. Florianópolis: Fundação Boiteux, 2012. 
de métodos e de técnicas aceitáveis, a noção de êxitos esperados ${ }^{51}$.

Daí o olhar mais aproximado, para compreender o tema proposto, concedendo visibilidade a características antes submersas na homogeneização e dicotomia com a qual é tratado o direito privado pela doutrina tradicional e pela representação e habitus com relação à propriedade privada, a partir da inclusão dos não proprietários no conceito constitucionalizado e aberto desse instituto, tendo por pressuposto o reconhecimento da realidade diferenciada desses grupos tradicionais.

\section{PERTENCIMENTO JURídICO: PRÁTICAS LOCAIS E RECONHECIMENTO LEGAL}

Um contraponto à propriedade privada é ressaltado por Paolo Grossi, quando se refere à propriedade coletiva como "antitética" ao que o Ocidente compreende por propriedade, "em que a titularidade não é nem do indivíduo nem do ente, mas da concatenação incessante das gerações dos consortes" ${ }^{2}$, ou seja, não considera, nesse tipo, o domínio do bem pela pessoa jurídica (como o faz a legislação brasileira quanto às terras quilombolas, por exemplo). Em suas mais diversas formas, o autor reconhece pontos em comum na apropriação coletiva: suporte de sobrevivência da comunidade; valor e função alimentar; fruição condicionada do bem; predominância do ordenamento comunitário sobre o indivíduo; ausência de jus disponendi.

No entanto, pela preponderância da mentalidade privatística do direito moderno, nosso sistema jurídico opera, conforme visto, por padrões eminentemente econômicos e individuais. A possibilidade de se regular um pertencimento coletivo de cunho privado é de difícil concretização. Na relação complexa que forma a propriedade quilombola, o direito exercido pelas quebradeiras de coco ou pelas comunidades de fundo de pasto, prepondera a racionalidade da dignidade do grupo e de sua coesão, em detrimento da lógica meramente econômica: os institutos tradicionais de direito privado não alcançam o pleno significado de seu exercício e tutela ${ }^{53}$.

Tais formas existentes no direito nacional possuem aproximação com aquela

\footnotetext{
51 TAROZZI, Massimiliano. O Que É a Grounded Theory? metodologia de pesquisa e de teoria fundamentada nos dados. Tradução de Carmem Lussi. Petrópolis: Vozes, 2011, p. 103.

52 GROSSI, Paolo. História da propriedade e outros ensaios. Rio de Janeiro: Renovar, 2006, p. 08.

53 PILATI, José Isaac. Propriedade e função social na pós-modernidade. 2. ed. Rio de Janeiro: Lumen Juris, 2012.
} 
descrita por Grossi. As comunidades de fundo de pasto, na Bahia, foram banidas de terras devolutas que cultivavam por gerações (desde o séc. XVII), privatizadas pelo processo de colonização brasileiro ${ }^{54}$. Hoje, estão reguladas pela Constituição do Estado, em seu art. 178 e parágrafo: reconhecendo o uso e o cultivo comunitário da terra, o ente público outorga direito real de concessão de uso, gravado por cláusula de inalienabilidade, à associação constituída para este fim ${ }^{55}$. Possuem concessão de direito real de uso (art. 1.225, XII, CC/2002), segundo a letra da Constituição do Estado da Bahia, com os consequentes direitos de usar e fruir livremente dos benefícios da terra, desde que sem contrariar a destinação de manutenção do grupo. Esse direito real, que pode ser gravado tanto em terras públicas quanto particulares, é concedido por prazo indeterminado para fins de cultivo da terra.

As quebradeiras de coco de babaçu, por sua vez, tiveram o acesso negado aos palmeirais a partir da Lei de Terras $\mathrm{n}^{0} 2.979$, de 17 de julho de 1969, do Estado do Maranhão, que concedeu terras a grandes projetos industriais e agropecuários, acarretando o cercamento de áreas antes consideradas públicas ${ }^{56}$. Hoje, seu direito de uso está reconhecido no art. 196 da Constituição maranhense (dezembro de $2007)^{57}$ e em diversas leis municipais desse Estado, e dos Estados do Tocantins e

${ }_{54}$ PINHEIRO, Rosalice Fidalgo; VAZ, Idovilde de Fátima Fernandes. Funções Sociais das Propriedades: a realização de direitos fundamentais nas situações proprietárias. Cadernos da Escola de Direito e Relações Internacionais, Curitiba, n. 15, p. 123-150, 2011.

55 "Art. 178 - Sempre que o Estado considerar conveniente, poderá utilizar-se do direito real de concessão de uso, dispondo sobre a destinação da gleba, o prazo de concessão e outras condições. Parágrafo único - No caso de uso e cultivo da terra sob forma comunitária, o Estado, se considerar conveniente, poderá conceder o direito real da concessão de uso, gravado de cláusula de inalienabilidade, à associação legitimamente constituída e integrada por todos os seus reais ocupantes, especialmente nas áreas denominadas de Fundos de Pastos ou Fechos e nas ilhas de propriedade do Estado, vedada a este transferência do domínio". BAHIA. Constituição do Estado da Bahia. Promulgada em 05 de outubro de 1989. Disponível em: < http://www.mp.ba.gov.br/ institucional/legislacao/constituicao_bahia.pdf>. Acesso em: 10 fev. 2015.

56 CORDEIRO, Renata dos Reis. "Babaçu Livre": a enunciação do conflito no campo jurídico pelas quebradeiras de coco, no Maranhão. In: ENCONTRO ANUAL DA ASSOCIAÇÃO NACIONAL DE PÓS-GRADUAÇÃO EM CIÊNCIAS SOCIAIS, 30., 2006, Caxambu. Anais.... Disponível em: < http://www.anpocs.org/portal/index.php?option $=$ com_docman\&task=doc_view\&gid=3225\&Itemid=232>. Acesso em: 10 fev. 2015.

57 "Art. 196. Os babaçuais serão utilizados na forma da lei, dentro de condições que assegurem a sua preservação natural e do meio ambiente, e como fonte de renda do trabalhador rural. Parágrafo único. Nas terras públicas e devolutas do Estado assegurar-se-á a exploração dos babaçuais em regime de economia familiar e comunitária". MARANHÃO. Constituição do Estado do Maranhão. Promulgada em 05 de outubro de 1989. Disponível em: < http://www2.senado.gov.br/bdsf/bitstream/id/70443/20/CE_Maranhao.pdf > . Acesso em: 10 fev. 2015. 
Pará (desde 1999) ${ }^{58}$. Nas disposições legais que regulam a prática das quebradeiras de coco (art. 1.225, V, CC/2002), o usuário pode usar o bem, desfrutá-lo, mas apenas recebe uma parte dos frutos, o suficiente para a subsistência dele e de sua família (art. 1.412, CC/2002): jus utendi (direito de usar) e jus fruendi (direito de fruir), este de maneira parcial. Daí que as comunidades podem usar dos cocos, desfrutálos, mas apenas recebem a parte suficiente para a sua manutenção.

Sua prática familiar de colher os frutos das palmeiras e extrair-lhes amêndoas possui livre acesso a propriedades públicas (Constituição Estadual) e privadas (leis municipais), sendo de uso comum por toda a comunidade: daí porque se entende que os palmeirais tornam-se, segundo sua finalidade, em bens principais (e não secundários em relação ao solo) para essas famílias ${ }^{59}$. A derrubada das árvores, queimadas e cultivo de plantações que possam trazer prejuízo ao seu desenvolvimento são proibidas, a fim de proteger a sobrevivência dessas pessoas, garantindo a extração realizada em regime de economia familiar e comunitária ${ }^{60}$.

O uso comum pelo grupo dos palmeirais será feito em quantidade adequada à sua manutenção, entendendo-se mantidas as faculdades do proprietário, inclusive particular, sobre a terra e as palmeiras não incluídas na área demarcada para a comunidade $^{61}$. A justificativa da Lei Municipal no 005/1997 de Lago do Junco (MA) demonstra a preocupação do legislador em aliar a normatização jurídica à realidade social, podendo-se observar, igualmente, a concretização da função social da posse e da propriedade:

É visível que a atividade extrativista do babaçu é a principal fonte de emprego e renda do nosso município, contribuindo para a diminui-

\footnotetext{
${ }^{58}$ Dentre outros municípios: Governador Archer, Lago do Junco, São Luiz Gonzaga (MA), Buriti, Praia do Norte (TO) e São Domingos do Araguaia (PA). CORDEIRO, Renata dos Reis. "Babaçu Livre": a enunciação do conflito no campo jurídico pelas quebradeiras de coco, no Maranhão. In: ENCONTRO ANUAL DA ASSOCIAÇÃO NACIONAL DE PÓS-GRADUAÇÃO EM CIÊNCIAS SOCIAIS, 30., 2006, Caxambu. Anais.... Disponível em: < http:// www.anpocs.org/portal/index.php?option $=$ com_docman\&task $=$ doc_view\&gid $=3225 \& I t e m i d=232>$. Acesso em: 10 fev. 2015; MATOS, Micheline. Quebrädeiras de coco do Māranhão: lutas e conquistas. ADITAL: Notícias da América Latina e Caribe. Disponível em: < http://www.adital.com.br/site/noticia2.asp?lang=PT\&$\operatorname{cod}=15040>$. Acesso em: 10 fev. 2015; JORNAL PEQUENO. Quebradeiras de Coco aprovam lei. Disponível em: $\quad<$ http://www.jornalpequeno.com.br/2012/9/18/quebradeiras-de-coco-aprovam-lei-e-comecam-a-fazer -parte-de-programa-que-garante-220666.htm > . Acesso em: 10 fev. 2015.

59 AGOSTINHO, Luane Lemos Felicio. As Leis do Babaçu Livre: uma análise do processo de juridicização das práticas sociais das mulheres quebradeiras de coco babaçu como expressão do pluralismo jurídico multicultural. Dissertação apresentada ao Mestrado em Direito Ambiental da Universidade do Estado do Amazonas. Manaus, 2010.

${ }^{60}$ PINHEIRO, Rosalice Fidalgo; VAZ, Idovilde de Fátima Fernandes. Funções Sociais das Propriedades: a realização de direitos fundamentais nas situações proprietárias. Cadernos da Escola de Direito e Relações Internacionais, Curitiba, n. 15, p. 123-150, 2011.

${ }^{61}$ OLIVEIRA, Fernando José Vianna. As Quebradeiras de Coco Babaçu e a Lei do Coco Livre. Disponível em: $<$ http://www.conteudojuridico.com.br/artigo,as-quebradeiras-de-coco-babacu-e-a-lei-do-coco-livre,32532. html >. Acesso em: 10 fev. 2015.
} 
ção dos problemas sócio administrativos do município, haja vista ser a Prefeitura Municipal a única geradora de emprego. Justifica-se a razão e interesse social e econômico do projeto. É justo, pois, que a Câmara Municipal torne a atividade livre, onde a classe beneficiadora tenha livre acesso à propriedade garantindo o seu sustento e de sua família ${ }^{62}$.

Quanto à propriedade quilombola, os títulos reconhecem o pertencimento não mais concebido para um indivíduo, abstratamente considerado. Ela será utilizada por uma coletividade cuja representação da propriedade foi construída em bases genuínas não albergadas, inicialmente, pelo arcabouço jurídico civilista brasileiro.

Na propriedade estabelecida pelo art. 68 ADCT, o sujeito é uma associação, representando toda uma comunidade, cujos integrantes farão uso comum de espaços destinados à manutenção dos modos de vida, da reprodução cultural, da coesão do grupo e uso individual e familiar de casas e quintais. $\mathrm{O}$ bem, assim, supera a dicotomia público/privado, incluindo espaços comuns e espaços de manutenção da vida privada.

Tais categorias jurídicas abarcam sede constitucional, regramento próprio, não exatamente encaixado em normas civilistas, gestão coletiva, função cultural e não meramente econômica. Elas são exemplo da dinamicidade proprietária, de sua complexidade de relações, superando a visão iluminista de direito subjetivo, imposto ao erga omnes. Percebe-se, enfim, que sob o manto da propriedade privada, toda uma gama de formas de pertencimento viceja.

\section{CONSIDERAÇÕES FINAIS}

O direito é um artefato cultural durante muito tempo marcado por escolhas que culminaram na sua extrema privatização. Hoje, compreende-se que mais do que o patrimônio, são as pessoas e seus agrupamentos - em suas dimensões multiculturais - que se encontram amparados pelo sistema jurídico nacional. A aplicação de institutos civilistas sob uma hermenêutica constitucionalmente adequada leva em consideração essa realidade, reorganizando a estruturação do sistema jurídico, agora fundado em valores eleitos pela Carta Magna. A repersonalização de institutos

${ }^{62}$ Lei Municipal ${ }^{0}$ 005/1997 de Lago do Junco (MA) disponibilizada por AGOSTINHO, Luane Lemos Felicio. As Leis do Babaçu Livre: uma análise do processo de juridicização das práticas sociais das mulheres quebradeiras de coco babaçu como expressão do pluralismo jurídico multicultural. Dissertação apresentada ao Mestrado em Direito Ambiental da Universidade do Estado do Amazonas. Manaus, 2010. 
centrais ao direito privado modifica a antiga mentalidade e as representações eminentemente individualistas, pondo em relevo o interesse social, abrangendo não somente a classe proprietária, mas igualmente os despossuídos e não proprietários.

Conforme se verificou, inúmeras formas de pertencimento existem em nosso território: comunidades quilombolas, de fundo de pasto, quebradeiras de coco do babaçu, dentre outras tantas possíveis de serem elencadas. Nos casos referidos, observa-se o uso comum da terra, para a subsistência familiar. Da mesma forma, as pessoas que compõem esses grupos compartilham vivências e costumes, trocas solidárias e construção de identidades. Percebe-se que a função social da propriedade e da posse impõe, por vezes, deveres aos proprietários de disponibilizar a terra e seus acessórios ao uso e fruição de não proprietários.

Dessa forma, o estatuto do pertencimento, visualizado por essa perspectiva, permite uma leitura muito mais conectada com as realidades locais. Os três casos aqui referidos contrariam o conceito unitário de propriedade, pois têm fundamentos outros que não apenas o direito oitocentista, abrangendo uma diversa gama de elementos socioantropológicos.

\section{REFERÊNCIAS}

ADROGUÉ, Manuel I. El Derecho de Propriedad em la Actualidad: introduccion a sus nuevas expressiones. Buenos Aires: Abeledo-Perrot, 1991.

AGOSTINHO, Luane Lemos Felicio. As Leis do Babaçu Livre: uma análise do processo de juridicização das práticas sociais das mulheres quebradeiras de coco babaçu como expressão do pluralismo jurídico multicultural. 2010. Dissertação (Mestrado em Direito Ambiental) - Universidade do Estado do Amazonas, Manaus, 2010.

ALVIM, Arruda. Livro Introdutório ao Direito das Coisas e o Direito Civil. Vol. XI, Tomo I. In: ALVIM, Arruda; ALVIM, Thereza; CLÁPIS, Alexandre Laizo (Coord.). Comentários ao Código Civil Brasileiro. Rio de Janeiro: Forense, 2009.

ANDRADE, Fabio Siebeneichler de. Considerações sobre a tutela dos direitos da personalidade no Código Civil de 2002. In: SARLET, Ingo Wolfgang (Org.). O Novo Código Civil e a Constituição. 2. ed. Porto Alegre: Livraria do Advogado, 2006. 
BAHIA. Constituição do Estado da Bahia. Promulgada em 05 de outubro de 1989. Disponível em: <http://www.mp.ba.gov.br/institucional/legislacao/constituicao_ bahia.pdf $>$. Acesso em: 10 fev. 2015.

BARATA, Pedro Paulo Barradas. A Constituição e o Código Civil: reflexões sobre a eficácia dos direitos fundamentais. Revista de Direito Privado, São Paulo, ano 10, n. 37, p. 185-207, jan./mar. 2009.

BEVILAQUA, Clóvis. Código Civil dos Estados Unidos do Brasil Comentado por Clóvis Bevilaqua. Rio de Janeiro: Rio, 1979. (Edição Histórica).

BOURDIEU, Pierre. A economia das trocas linguísticas: o que falar quer dizer. São Paulo: EDUSP, 1996.

CANOTILHO, José Joaquim Gomes. Direito Constitucional e Teoria da Constituição. 7. ed. Coimbra: Almedina, 2003.

CIRNE, Mariana Barbosa. A (Pré) Compreensão de uma Propriedade que Trabalha contra sua Função Social. In: CONGRESSO NACIONAL DE PESQUISA E PÓSGRADUAÇÃO EM DIREITO, 19., 2010, Fortaleza. Anais... Florianópolis: Fundação Boiteux, 2010. Disponível em: < http://www.conpedi.org.br/manaus/arquivos/anais/ fortaleza/Integra.pdf $>$. Acesso em: 02 jan. 2015.

COLAÇO, Thais Luzia; DAMÁZIO, Eloise da Silveira Petter. Novas perspectivas para a antropologia jurídica na América Latina: o direito e o pensamento decolonial. Florianópolis: Fundação Boiteux, 2012.

CORDEIRO, Renata dos Reis. "Babaçu Livre": a enunciação do conflito no campo jurídico pelas quebradeiras de coco, no Maranhão. In: ENCONTRO ANUAL DA ASSOCIAÇÃO NACIONAL DE PÓS-GRADUAÇÃO EM CIÊNCIAS SOCIAIS, 30., 2006, Caxambu. Anais... Disponível em: <http://www.anpocs.org/portal/index. php?option $=$ com_docman\&task $=$ doc_view\&gid $=3225 \&$ Itemid $=232>$. Acesso em: 10 fev. 2015.

CORTIANO JÚNIOR, Eroulhts. O discurso jurídico da propriedade e suas rupturas: Uma análise do ensino do Direito de Propriedade. Rio de Janeiro: Renovar, 2001. 
DAVID, René. Os grandes sistemas do direito contemporâneo. Tradução de Hermínio A. Carvalho. 3. ed. São Paulo: Martins Fontes, 1996.

DUGUIT, León. Las Transformaciones Generales del Derecho Privado desde el Código de Napoleón. 2. ed. Tradução de Carlos Pousada. Madrid: Francisco Beltran Libreria, 1912.

FACHIN, Luiz Edson. A função social da posse e da propriedade contemporânea: uma perspectiva da usucapião imobiliária rural. Porto Alegre: Sérgio Antônio Fabris, 1988.

GILISSEN, John. Introdução histórica ao Direito. Tradução de António Manuel Hespanha e L. M. Macaísta Malheiros. 4. ed. Lisboa: Fundação Calouste Gulbenkian, 2003.

GROSSI, Paolo. História da propriedade e outros ensaios. Rio de Janeiro: Renovar, 2006.

HESPANHA, António Manuel. Cultura jurídica europeia: síntese de um milénio. 3. ed. Mem Martins: Europa-América, 2003.

JORNAL PEQUENO. Quebradeiras de Coco aprovam lei. Disponível em: < http:// www.jornalpequeno.com.br/2012/9/18/quebradeiras-de-coco-aprovam-lei-ecomecam-a-fazer-parte-de-programa-que-garante-220666.htm > . Acesso em: $10 \mathrm{fev}$. 2015.

KANT, Immanuel. Resposta à pergunta: que é esclarecimento? Disponível em: <www.ufsm.br/gpforma/2senafe/PDF/b47.pdf>. Acesso em: 03 jan. 2015 (sem indicação do tradutor).

$\mathrm{KICH}$, Bruno Canísio. A propriedade na ordem jurídica econômica e ideológica. Porto Alegre: Sérgio Antônio Fabris, 2004.

LIMA, Getúlio Targino. Propriedade: crise e reconstrução de um perfil conceitual. São Paulo: SRS, 2009.

LISBOA, Roberto Senise. Dignidade e solidariedade civil-constitucional. Revista de Direito Privado, São Paulo, ano 11, v. 42, p. 30-70, abr./jun., 2010. 
LOBO, Paulo Luiz Neto. Direito Civil Alternativo. In: CHAGAS, Silvio Donizete (Org.). Lições de direito civil alternativo. São Paulo: Acadêmica, 1994.

MARANHÃO. Constituição do Estado do Maranhão. Promulgada em 05 de outubro de 1989. Disponível em: < http://www2.senado.gov.br/bdsf/bitstream/id/70443/20/ CE_Maranhao.pdf $>$. Acesso em: 10 fev. 2015.

MATOS, Micheline. Quebradeiras de coco do Maranhão: lutas e conquistas. ADITAL: Notícias da América Latina e Caribe. Disponível em: < http://www.adital. com.br/site/noticia2.asp?lang $=$ PT\&cod $=15040>$. Acesso em: 10 fev. 2015.

MENDES, Gilmar Ferreira; COELHO, Inocêncio Mártires; BRANCO, Paulo Gustavo Gonet. Curso de Direito Constitucional. 5. ed. São Paulo: Saraiva, 2010.

MÉXICO. Constituição Mexicana de 1917. Disponível em: < http://www.diputados. gob.mx/LeyesBiblio/pdf/1.pdf> . Acesso em: 23 nov. 2014.

NASCIMENTO, Tupinambá Miguel Castro do. Posse e Propriedade. 3. ed. Porto Alegre: Livraria do Advogado, 2003.

OLIVEIRA, Fernando José Vianna. As Quebradeiras de Coco Babaçu e a Lei do Coco Livre. Disponível em: <http://www.conteudojuridico.com.br/artigo,asquebradeiras-de-coco-babacu-e-a-lei-do-coco-livre,32532.html> . Acesso em: $10 \mathrm{fev}$. 2015.

ORLEANS, Helen Cristina Leite de Lima. Não basta ser proprietário, tem que participar: algumas notas sobre a função social da propriedade imobiliária no Direito brasileiro. Revista de Direito Privado, São Paulo, ano 12, v. 46, p. 99-147, abr.jun. 2011.

PAULSEN, Leandro. A normatividade jurídico-positiva da função social da propriedade. Revista da AJUFERGS, Porto Alegre, n. 02, p. 61-106, 2006.

PERLINGIERI, Pietro. O Direito civil na legalidade constitucional. Tradução de Maria Cristina de Cicco. Rio de Janeiro: Renovar, 2008.

PILATI, José Isaac. Propriedade e função social na pós-modernidade. 2. ed. Rio de Janeiro: Lumen Juris, 2012. 
PINHEIRO, Rosalice Fidalgo; VAZ, Idovilde de Fátima Fernandes. Funções sociais das propriedades: a realização de direitos fundamentais nas situações proprietárias. Cadernos da Escola de Direito e Relações Internacionais, Curitiba, n. 15, p. 123150, 2011.

PUGLIATTI, Salvatore. La Proprietà nel Nuovo Diritto. Milano: Dott. A. Giuffrè, 1964.

RODOTÁ, Stefano. El Terrible Derecho: estúdios sobre la propriedad privada. Tradução de Díez-Picazo. Madrid: Civitas, 1986.

ROULAND, Norbert. Nos confins do direito. Tradução de Maria Ermantina de Almeida Prado Galvão. 2. ed. São Paulo: Martins Fontes, 2008.

SANTOS, Boaventura de Sousa. A Crítica da razão indolente: contra o desperdício da experiência. Para um novo senso comum: a ciência, o direito e a política na transição paradigmática. 3. ed. São Paulo: Cortez, 2001.

SARLET, Ingo Wolfgang. A Eficácia dos direitos fundamentais: uma teoria geral dos direitos fundamentais na perspectiva constitucional. 10. ed. Porto Alegre: Livraria do Advogado, 2010.

TAROZZI, Massimiliano. O que é a Grounded Theory? metodologia de pesquisa e de teoria fundamentada nos dados. Tradução de Carmem Lussi. Petrópolis: Vozes, 2011.

TEPEDINO, Gustavo; SCHREIBER, Anderson. A Garantia da propriedade no direito brasileiro. Revista da Faculdade de Direito de Campos, ano VI, n. 06, p. 101-119, jun., 2005.

TORRES, Marcos Alcino de Azevedo. A propriedade e a posse: um confronto em torno da função social. 2. ed. Rio de Janeiro: Lumen Juris, 2010. 
